\title{
KONTRIBUSI BUDAYA LOKAL GAWAI DALAM MENUMBUHKAN NILAI SOLIDARITAS GENERASI Z PADA SUKU DAYAK MUALANG
}

\author{
Fusnika, Falentina Lestiana Dua \\ STKIP Persada Khatulistiwa, Pendidikan Pancasila dan Kewarganegaraan, Sintang \\ Email: funsika804@gmail.com, lesiana0299@gmail.com
}

\begin{abstract}
This study aims to determine the contribution of the local culture of gawai in growing the value of Generation $Z$ Solidarity in the Dayak Mualang Tribe. The problem in this study is how the process of implementing Gawai in the Dayak Mualang tribe, how the contribution of Gawai in growing social awareness and the value of sodidarity in generation $Z$ in the Dayak Mualang Tribe. The method used in this research is descriptive qualitative. Data collection techniques used were observation, interview, and documentation study, while the data collection tools were observation guides, interview guides, and documentation. The results showed that the Local Culture of Gawai in the Dayak Mualang Tribe is still well preserved with the implementation of Gawai routinely every year. Dayak Gawai contributes to growing social awareness and the value of generation $Z$ solidarity in the Dayak Mualang Tribe.
\end{abstract}

Keywords: Local Culture, Solidarity Values, Social Awareness, Generation Z, Dayak Mualang 


\begin{abstract}
Abstrak
Penelitian ini bertujuan untuk mengetahui kontribusi budaya lokal gawai dalam menumbuhkan Nilai Solidaritas Generasi Z Pada Suku Dayak Mualang. Masalah dalam penelitian ini adalah bagaimana proses pelaksanaan Gawai pada suku Dayak Mualang, bagaimana kontribusi Gawai dalam menumbuhkan kesadaran sosial dan nilai sodidaritas pada generasi Z Pada Suku Dayak Mualang. Metode yang digunakan dalam penelitian ini adalah kualitatif deskriptif. Teknik pengumpulan data yang digunakan adalah teknik observasi, wawancara, dan studi dokumentasi, Sedangkan alat pengumpulan data adalah panduan observasi, panduan wawancara, dan dokumentasi. Hasil penelitian menunjukkan bahwa Budaya Lokal Gawai pada Suku Dayak Mualang masih terlestarikan dengan baik dengan terlaksananya Gawai secara rutin setiap tahunnya. Gawai Dayak memberi kontribusi dalam menumbuhkan kesadaran sosial dan nilai solidaritas generasi Z Pada Suku Dayak Mualang.
\end{abstract}

Kata kunci: Budaya Lokal, Nilai Solidaritas, Kesadaran Sosial, Generasi Z, Dayak Mualang 


\section{A. Pendahuluan}

Generasi $\mathrm{Z}$ adalah generasi yang lahir pada tahun - tahun awal dari perkembangan teknologi dan informasi seperti penggunaan video games, TV kabel, dan internet. Ciri - ciri dari generasi ini adalah: mampu beradaptasi, mampu menerima perubahan dengan baik dan disebut sebagai generasi yang tangguh, memiliki karakter mandiri dan loyal, sangat mengutamakan citra, ketenaran, dan uang, tipe pekerja keras, menghitung kontribusi yang telah diberikan perusahaan terhadap hasil kerjanya (Jurkiewicz, 2000).

Generasi ini banyak menggunakan teknologi komunikasi instan seperti email, SMS, instant messaging dan media sosial seperti facebook dan twitter, dengan kata lain generasi $\mathrm{Z}$ adalah generasi yang tumbuh pada era internet booming. Lebih lanjut (Lyons, 2004) mengungkapkan ciri - ciri dari generasi $\mathrm{Z}$ adalah: karakteristik masing-masing individu berbeda, tergantung dimana ia dibesarkan, strata ekonomi, dan sosial keluarganya, pola komunikasinya sangat terbuka dibanding generasi-generasi sebelumnya, pemakai media sosial yang fanatik dan kehidupannya sangat terpengaruh dengan perkembangan teknologi, sehingga mereka terlihat sangat reaktif terhadap perubahan lingkungan yang terjadi di sekelilingnya. Tetapi pada generasi $\mathrm{Z}$ kesadaran sosialnya dan moralnya melemah dari generasi sebelumnya, terkadang terkesan cuek pada apa yang terjadi di sekitarnya. Kebanyakan generasi $\mathrm{Z}$ terlaku fokus pada gadget yang dipegangnya sehingga lingkungan disekitarnya terabaikan.
Kebudayaan diwariskan secara turun-tenurun, dari satu generasi ke generasi lainnya. Proses pewarisan kebudayaan disebut juga sebagai proses inkulturasi. Gawai merupakan salah satu hasil kebudayaan masyarakat Suku Dayak yang masih berkembang sampai saat ini dan telah menjadi tradisi rutin tahunan serta sebagai suatu wujud dan ciri khas budaya lokal pada suku Dayak Mualang. Gawai merupakan wujud syukur kepada Tuhan atas kelimpahan hasil pertanian dan meminta kelimpahan ditahun selanjutnya, hal ini di ungkapkan juga oleh Aswin dalam Akcaya.( 1994: 03) bahwa "Upacara Naik Dango merupakan ungkapan rasa syukur atas keamanan, kesehatan, dan hasil panen yang melimpah, selain itu berusaha mencari terobosan baru sebagai usaha meningkatkan hasil pertanian pangan'. pada Suku Dayak mualang Gawai Dayak dikenal sama prinsipnya dengan Naik Dango.

Menurut Bahari, dkk. (1999: 243) makna upacara Naik Dango antara lain, adalah; a) Mensyukuri karunia Jubata, b) Mohon restu kepada Jubata untuk menggunakan padi yang telah disimpan di dangao padi, c) Pertanda penutupan tahun berladang, d) Mempererat hubungan persaudaraan atau solidaritas. Gawai Dayak menyumbangkan nilai-nilai penting dalam kehidupan sosial masyarakat Suku Dayak Mualang terutama bagi generasi muda atau lebih terkhusus pada generasi $\mathrm{Z}$, sebuah generasi yang kesadaran sosialnya dan moralnya melemah dan terkadang terkesan cuek pada apa yang terjadi di sekitarnya . Gawai memberikan kontribusi dalam 
menumbuhkan nilai-nilai solidaritas antar sesama.

Menurut Teodorus dalam Basrowi, (2005: 79) mengemukakan bahwa nilai merupakan sesuatu yang abstrak yang dijadikan pedoman serta secara prinsipprinsip umum dalam bertindak dan bertingkah laku. Sedangkan Menurut Durkheim dalam Lawang (1994:181) solidaritas menunjukkan pada hubungan antara individu dan atau kelompok yang didasarkan pada perasaan moral dan kepercayaan dianut bersama yang diperkuat oleh pengalaman emosional bersama. Solidaritas menekankan pada keadaan hubungan antar individu dan kelompok dan mendasari keterikatan bersama dalam kehidupan dengan didukung nilai-nilai moral dan kepercayaan yang hidup dalam masyarakat.

Wujud nyata dari hubungan bersama akan melahirkan pengalaman emosional, sehingga memperkuat hubungan antar mereka. Berdasarkan pengertian di atas dapat disimpulkan bahwa solidaritas adalah keadaan dimana individu merasa telah menjadi bagian dari sebuah kelompok atau masyarakat. Atas dasar perasaan moral, kepercayaan serta pengalaman emosional bersama dan ikatan daerah, sehingga memperkuat dan mempererat hubungan antar sesama.

Banyak generasi muda yang rasa kebersamaan serta solidaritas mulai menghilang dan terkikis oleh karena halhal seperti menempuh pendidikan diluar, kekota - kotakan dalam pergaulan sehari-hari, lingkungan bermain dan sebagainya oleh karena itu peneliti tertarik untuk melakukan penelitian ini. Selain itu, dalam pelaksanaan Gawai Dayak generasi $\mathrm{Z}$ berkumpul dan mendominasi dalam pelaksanaan Gawai terutama para pelajar dan kaum muda suku Dayak mualang tang terdapat di Desa Sepauh Kabupaten Sekadau. Berdasarkan uraian diatas, dengan penelitian ini peneliti tertarik untuk mendeskripsikan dan menggambarkan serta mempelajari secara mendalam mengenai budaya lokal untuk mengetahui Kontribusi budaya lokal gawai dalam menumbuhkan Nilai Solidaritas Generasi Z Pada Suku Dayak Mualang.

\section{B. Metode}

Dalam penelitian ini peneliti menggunakan metode kualitatif deskriptif. Menurut Satori (2011: 199) menyatakan bahwa penelitian kualitatif atau disebut juga penelitian naturalistik adalah pendekatan penelitian yang menjawab permasalahan penelitiannya memerlukan pemahaman secara mendalam dan menyeluruh mengenai objek yang diteliti. Untuk menghasilkan kesimpulan-kesimpulan penelitian dalam konteks waktu dan situasi yang bersangkutan.

Lokasi penelitian adalah di Desa Sepauh Kecamatan Balai sepuak Kabupaten Sekadau. Instrument penelitian adalah peneliti itu sendiri. Hal yang sama juga diungkapkan oleh Satori (2011: 61), Instrumen dalam penelitian kualitatif adalah yang melakukan penelitian itu sendiri yaitu peneliti. Peneliti dalam penelitian kualitatif merupakan orang yang membuka kunci, 
menelaah dan mengeksplorasi seluruh ruang secara cermat, tertib, dan leluasa. Sumber data primer dalam penelitian ini adalah informan kunci Lima generasi $\mathrm{Z}$ merupakan generasi setelah Generasi Y, yang didefenisikan sebagai orang-orang yang lahir dalam rentang tahun kelahiran 1995 sampai 2010 Desa Sepauh, untuk memperkuat hasil penelitian ini, peneliti menambahkan informan pendukung yaitu tokoh masyarakat dan Adat serta penduduk desa Sepauh yang telah memahami dan mengerti mengenai Gawai Dayak yang merupakan penduduk Desa Sepauh dan Suku Dayak Mualang.

Teknik pengumpulan data merupakan metode yang digunakan peneliti dalam memperoleh informasi yang dibutuhkan dalam rangka mencapai tujuan penelitian. Menurut Sugiyono (2011:224), Teknik pengumpulan data merupakan langkah yang paling strategis dalam penelitian, karena tujuan utama dari penelitian adalah mendapatkan data.

Tanpa mengetahui teknik pengumpulan data, maka peneliti tidak akan mendapatkan data yang memenuhi standar data yang ditetap. Oleh karena itu peneliti melakukan 3 teknik dalam pengumpulan data yaitu melalui observasi kepada kelima generasi muda dan tokoh masyarakat dan Adat, wawancara secara mendalam kepada informan kunci yaitu kelima generasi $\mathrm{Z}$ dan tokoh-tokoh penting desa Sepauh, serta studi dokumentasi.

kemudian analisis data dalam penelitian ini terdiri dari beberapa tahap seperti berikut: 1) Reduksi Data; reduksi data dalam penelitian ini terutama mengenai Gawai Dayak di desa Sepauh
Kecamatan Balai sepuak Kabupaten Sekadau yang disesuaikan dengan teoriteori yang dipakai dalam penelitian. Reduksi data dilakukan sejak mulai penelitian sampai selesai penelitian. 2) Penyajian Data; penyajian data adalah penyusunan informasi-informasi menjadi suatu pernyataan, data kualitatif disajikan dalam bentuk teks pada umumnya sesuai dengan pendapat seseorang yang beranekaragam pendapat dan pandangan.

Selanjutnya diklasifikasikan menurut pendapat para tokoh dan penduduk serta generasi muda. Tentunya dalam penelitian ini berkenaan dengan proses budaya lokal Gawai di desa Sepauh Kecamatan Balai sepuak Kabupaten Sekadau. 3) Kesimpulan; kesimpulan ditarik berdasarkan reduksi data dan penyajian data yang telah dilakukan pada setiap tahap-tahap penelitian sebelumnya.

\section{Pembahasan Dan Hasil 1. Pembahasan}

Suku Dayak Mualang adalah salah satu sub suku Dayak Iban yang mendiami Kabupaten Sekadau dan Kabupaten Sintang di Kalimantan Barat, Indonesia,. Salah satu ciri yang tampak pada orang suku Dayak Mualang adalah ciri fisik yang mongoloid, wajah bulat, kulit putih atauu kuning langsat, mata agak sipit, rambut lurus, ada juga yang ikal serta relatif tidak tinggi, dan juga dikenal dengan keramah-tamahannya, orang mualang sangat mudah membaur dengan sub suku lain.

Dayak Mualang adalah nama salah satu Suku Dayak yang terdapat di Kabupaten Sekadau Kalimantan Barat. 
Jumlah suku Dayak ini kurang lebih 65.000 jiwa (Florus,1992). Menurut tradisi mereka, mereka berasal dari (tempat warisan leluhur) Temawang Tampun Juah, di daerah Saih (anak Sungai Ketungau) dan Sungai Sekayam. Kebanyakan dari kelompok yang disebutkan di atas sama seperti Dayak dari Sanggau dan Dayak Sadong di Sarawak, juga mengatakan bahwa Tembawang inilah sebagai daerah asal mereka yang sebenarnya menurut Dunselman, (1955). Berdasarkan ciri Ehtnoluinguistic dan ciri kebudayaan, Dayak Mualang termasuk salah satu kelompok Dayak Iban. Ciri tersebut berdasarkan sastra lisan bekana, bejandeh, sastra tua atau cerita-cerita turun temurun dan penokohan tokoh yang di puja pada masa lalu diantaranya: keling, kumang, laja, ijau, punggak, inai abang, belun belunan.

Mualang sendiri di populerkan karena terkait dengan seorang yang di puja yaitu: pahlawan, letnan yang di gelar Manok sabung / ayam aduan. karena si tokoh mualang tersebut merupakan seorang yang berani dan tak pernah mundur ia mempunyai semangat: "Agek Idop Agek Ngelaban'” ( masih hidup masih melawan )oleh sebab itu beliau di jadikan simbol kepahlawanan pada masa lalu.

Suku Dayak Mualang berasal dari daerah tampun juah (di daerah Segumon Kecamatan Balai Karangan, Kabupaten Sanggau)) yang berpindah ke daerah belitang kabupaten sekadau, menurut cerita nya di suatu daerah yang bernama tampun juah hidup lah sekelompok manusia yang sangat ramai sekali, dengan perumpamaan nya jika sebatang pohon kelapa di tebang pada pagi hari, maka pada sore hari nya pohon itu akan menjadi rata dengan tanah karena di injak oleh manusia yang lalu lalang di daerah tersebut,, atau bila seekor burung elang sedang terbang di atas pemukiman mereka, burung itu pasti akan jatuh terkena asap dapur ibu-ibu yang sedang memasak.

Di namakan tampun juah, konon cerita nya waktu itu di daerah tersebutAturan satu-satunya adalah tidak memperbolehkan pernikahan orang yang masih terikat hubungan darah. Bila aturan ini dilanggar, malapetaka akan terjadi di bumi. Untuk menghentikan malapetaka tersebut mempelai haram ini diikat dalam keadaan berpelukan kemudian ditembuskan dengan tombak, kemudian mayat mereka dilemparkan ke sungai. Itu lah yang di alami juah dan sangka yang mana mereka melansungkan perkawinan sedangkan mereka masih ada hubungan keluarga karena ulah perbuatan mereka tersebut maka hukuman nya oleh kepala suku pasangan tadi di hukum mati dengan cara menancapkan kedua tubuh pelaku yang di ikat berpelukan dengan 'sangkoh' (tombak) hingga menembus tubuh kedua nya, kemudian mayat nya di buang atau di hayutkan di sungai ,maka atas peristiwa tersebut daerah itu di namakan tampun juah.,tampun artinya menghujam dan juah adalah nama dari salah satu pasangan tersebut.

Mualang adalah nama salah satu sub suku dayak yang ada di kabupaten sekadau, nama mualang di ambil dari nama seorang panglima perang yang tewas dalam perjalanan pulang dari mngayau (membunuh atau berperang 
melawan musuh) Dayak mualang ini tersebar di 3 kecamatan yaitu belitang hulu, belitang hilir, dan nanga beliatng, suku mualang merupakan suku terbesar di kabupaten sekadau, memiliki bahasa yang benadai,, suku ini merupakan suku yang terkenal dengan kebiasaan 'mengayau'. Mengayau merupakan kebiasaan dayak ini pada jaman dahulu sampai tahun 1970an, dayak mulang mempunyai tradisi dan adat istiadat di antaranya gawai, tarian perang, tari piring,

Dari hasil wawancara dan observasi kepada tokoh-tokoh Adat dan masyarakat serta pemuda di desa Sepauh dapat dikatakan bahwa Gawai Dayak merupakan ritual rutin tahunan Suku Dayak setelah panen padi yang merupakan warisan nenek moyang secara turun-temurun, yang merupakan ungkapan rasa syukur kepada Tuhan atas kelimpahan hasil pertanian. Kegiatan Gawai Dayak memiliki rangkaian kegiatan sebagai berikut: Sebelum pelaksanaan, seluruh masyarakat desa mempersiapkan hidangan makanan dan minuman khas daerah yang akan dihidangkan dalam pelaksanaan acara atau hari pesta Gawai Dayak, Saat hari pelaksanaan Gawai masyarakat saling mengunjungi dan menjalin silahturahmi satu sama lainnya baik antar generasi muda maupun para orang tua yang ada di desa Sekendal maupun masyarakat dan penduduk desa lainnya yang datang. Setelah itu Gawai Dayak berakhir. Dari hal tersebut terjadi kesesuaian antara teori yang diungkapkan dengan kenyataan yang ada dilapangan saat penelitian karena Gawai Dayak atau Naik Dango merupakan kegiatan yang dilakukan dan memiliki makna dan nilainilai yang sangat penting dalam keberadaan Suku-suku Dayak yaitu nilai-nilai keagamaan seperti menyembah dan bersyukur kepada Tuhan Yang Maha Esa, serta meminta kelimpahan hasil panen berikutnya dan dalam Gawai Dayak tampak adanya penanaman nilai-nilai solidaritas sosial seperti nilai perasaan Moral dan Kepercayaan bersama, dimana dalam Gawai Dayak generasi muda saling mengunjungi rumah-rumah keluarga dengan saling menghormati dan menunjukkan sopan santun, serta mempererat rasa kepercayaan bersama dengan menjalankan tradisi dan warisan nenek moyang bersama masyarakat. Kontribusi Gawai dalam Menumbuhkan Nilai Perasaan Moral pada Generasi muda Berdasarkan hasil observasi yang dilakukan pada generasi muda nilai-nilai perasaan moral dalam kalangan generasi muda tampak terlihat karena adanya rasa saling menghargai dan saling menghormati, dengan saling mengunjungi satu sama lainnya, sikap sopan santun terlihat saat Gawai dimana para pemuda desa saling mengunjungi sanak saudara dan teman. Nilai moral sangat dijunjung tinggi dalam pelaksanaan Gawai Dayak dengan saling menjalin tali persaudaraan dan kekeluargaan terlihat dalam Gawai Dayak baik generasi muda maupun para tuatua desa saling mengunjungi dan menjalin silahturahmi. Jadi Gawai Dayak merupakan kegiatan yang memiliki makna dan nilai solidaritas yang sangat penting dijaga terutama nilai perasaan moral, seperti saling menghormati, kerja sama dan nilai-nilai 
kearifan lokal yang ada di desa yang sangat penting dalam proses perlestarian budaya dan kebudayaan desa terutama Suku Dayak Mulang di Desa Sepauh.

$$
\text { Kontribusi Gawai dalam }
$$

Menumbuhkan kesadaran sosial dan nilai solidaritas pada generasi $\mathrm{Z}$, dari hasil observasi dan wawancara secara mendalam, Gawai Dayak merupakan tradisi rutin tahunan Suku Dayak yang merupakan ungkapan rasa syukur kepada sang pencipta sebagai warisan nenek moyang dalam suatu keyakinannya. Gawai Dayak memberikan kontribusi dalam penanaman nilai-nilai solidaritas sosial. Dalam Gawai Dayak terlihat adanya rasa kepercayaan bersama masyarakat seperti dimana dalam Gawai Masyakat menjalankan Ritual yang dipercaya merupakan rutinitas dan ungkapan rasa syukur kepada sang pencipta, selain itu Gawai Dayak dijalankan sebagai warisan generasi terdahulu yang sampai sekarang masih dijalankan oleh masyarakat desa Sekendal.

Jadi Gawai Dayak memberikan kontribusi dalam penanaman nilai-nilai solidaritas kepada generasi muda secara khusus nilai-nilai dan rasa kepercayaan dan keyakinan bersama masyarakat dimana dalam Gawai Dayak terlihat dan tersirat kebudayaan Suku Dayak Mualang yang merupakan warisan tradisi nenek moyang yang sampai saat ini masih dilaksanakan oleh sebagian besar Suku Dayak sebagai ungkapan rasa syukur kepada Tuhan.

\section{Hasil}

Desa Sepauh berada pada Kecamatan Balai sepauk Kabupaten
Sekadau, Kalimantan Barat. Penduduk desa Sepauh dipenuhi oleh mayoritas penduduk Suku Dayak Mualang yang merupakan penduduk asli desa Sepauh. Hasil observasi yang dilakukan pada generasi $\mathrm{Z}$ dan tokoh masyarakat adat diperoleh data sebagi berikut, proses pelaksanaan Gawai Dayak terdiri dari tiga tahap yaitu; proses pelaksanaan Gawai, pelaksanaan Gawai Desa Sekendal yang dilaksanakan pada tanggal 22 Juli 2019 di lakukan setelah rapat Adat dan musyawarah oleh ketua dan tokoh Adat Dayak desa Sepauh yang dilaksanakan satu (1) Bulan sebelum pelaksanaan Gawai dengan membentuk panitia. Acara Gawai Dayak berjalan setelah adanya penetapan tanggal dan dilakukan oleh masyarakat yang merayakan. Pelaksanaan Gawai; a. Sebelum acara, sebelum acara masyarakat dan semua penduduk Desa menyiapkan makanan dan minuman khas seperti Tuak, Pulut (lulun, tepung), dan makanan lainnya yang nantinya disajikan untuk tamu dan sanak saudara yang datang. b. Saat pelaksanaan Gawai, Pelaksanaan Gawai Dayak di Desa Sepauh sangat meriah biasanya disertai dengan acara pernikahan secara adat, para tamu baik dari desa Sepauh dan desa tetangga lainnya berdatangan dan memeriahkan acara Gawai Dayak ini. Sebagian besar para pemuda desa berkumpul dan memeriahkan acara Gawai Dayak. Para generasi muda saling berkumpul dan saling mengunjungi satu sama lainnya. c. Penutup, Gawai Dayak berakhir setelah menjelang malam, para tamu dan masyarakat pulang dengan membawa buah tangan baik minuman maupun makanan tradisional Dayak. 
Kontribusi Gawai Dayak dalam menumbuhkan nilai kesadaran sosial dan nilai solidaritas pada generasi $\mathrm{Z}$, terlihat dari hasil observasi bahwa pemuda Desa Sepauh memiliki rasa solidaritas yang tinggi, terlihat jelas dalam pelaksanaan Gawai generasi $\mathrm{Z}$ sangat antusias mengikuti Gawai dengan saling mengunjungi sanak saudara dan kerabat. Dalam Gawai dayak generasi muda tampak saling mengunjungi dengan saling menghormati serta sopan santun baik kepada sesama maupun kepada para tua-tua adat desa serta warga desa satu sama lainnya.

Kontribusi Gawai Dayak dalam menumbuhkan kepercayaan bersama pada generasi muda, Gawai Dayak merupakan tradisi rutin tahunan yang mana ditunjukan oleh para pemuda desa Sepauh sendiri tampak dengan mengikuti Ritual-ritual dan adat istiadat yang dianut oleh nenek moyang sebagai warisan budaya lokal adanya kegiatan dan pelaksanaan membuat sesaji dan melakukan ritual yang dalam kebudayaan Suku Dayak sudah menjadi kegiatan rutin Suku Dayak setelah pasca panen dan kegiatan budaya Dayak lainnya.

Dari data observasi dapat disimpulkan bahwa penduduk Desa Sepauh terutama generasi $\mathrm{Z}$ mempunyai rasa solidaritas sosial yang kuat hal ini terlihat dalam pelaksanaan Gawai Dayak yang dilaksanakan setiap tahunnya oleh masyarakat penduduk Desa Sepauh yang telah berlangsung selama bertahuntahun.

\section{Simpulan}

Maka dapat ditarik kesimpulan bahwa budaya lokal Gawai Dayak memberikan kontribusi dalam menanamkan kesadaran sosial dan nilai solidaritas sosial moral dan kepercayaan bersama pada generasi Z. Pelaksanaan Gawai Dayak di Desa Sepauh terdiri dari tahap persiapan, pelaksanaan dan penutupan. Gawai Dayak berkontribusi dalam menumbuhkan nilai solidaritas pada generasi $\mathrm{Z}$ dengan saling mengunjungi, saling bersilahturahmi dan memberikan salam serta berlaku sopan santun dalam berinteraksi antar sesama baik terhadap kaum muda atau teman sebaya maupun orang yang lebih tua.

Gawai Dayak berkontribusi dalam menumbuhkan rasa kepercayaan bersama dengan menjalankan kegiatan dan ritual serta adat istiadat Gawai yang dapat menanamkan rasa kepercayaan pada generasi muda dalam mengamalkan kebudayaan nenek moyang mereka demi menjaga kelestarian budaya lokal.

\section{Daftar Pustaka}

Akbar, S.P dan H. Usman. 2006. Metode Penelitian Sosial. Bumi Askara. Jakarta

Amri. 2013. Kearifan Lokal Lubuk Larangan Sebagai Upaya Pelestarian Sumberdaya Perairan Didesa Pangkalan Indrarung Kabupaten Kuatan Singing

Bahari, Herkulanus dkk. 2010. Tradisi Perladangan Dayak Kanayathn Binua Kaca' Kecamatan Menjalin Kabupaten Pontianak, Kalimantan Barat. Pontianak: Institue Dayakology Research And Development. 
Djam'ah dan Aan Komariah. (2011). Metodelogi Penelitian Kualitatif. Bandung: Penerbit Alfabeta. Sinju,

Fariani. 2014. Nilai pendidikan dalam kearifan lokal permainan tradisional anak Suku Batak dan Melayu. Dalam Bulitin Haba. Banda Aceh. Balai Pelestarian Niali Budaya.

Jurkiewicz, C. L. (2000). Generation X and the Public Employee. Public Personnel Management, $29(1), \quad 55$. https://doi.org/10.1177/00910 $\underline{2600002900105}$

Kapil, Y., \& Roy, A. 2014. Critical Evaluation of Generation $\mathrm{Z}$ at Workplaces. International Journal of Social Relevance \& Concern, II(1), 10-14.

Karakas, F., Manisaligil, A., \& Sarigollu, E. 2015. Management Learning at the Speed of Life: Designing Reflective, Creative, and Collaborative Spaces for Millenials. International Journal of Management Education, XIII(3), 237-248.

Lyons, S. (2004). An exploration of generational values in life and at work. ProQuest Dissertations and Theses, 441441 . Retrieved from http://ezproxy.um.edu.my/doc view/305203456? accountid=2 $\underline{8930}$

Moleong, Lexy J. (2011). Metodelogi Penelitian Kualitatif Edisi Revisi. Bandung: PT Remaja
Markus Willy Dkk. 1996. Kamus Inggris Indonesia-Indonesia Inggris. Surabaya. Arloka.

Muhammad Ramli. 2008. Sinergisitas Kearifan Lokal Bugis Dalam Mengimplementasikan

Kebijakan Publik Di Kabupaten Sidenreng Rappang, Disertasi. Universitas Hasanuddin. Makasar.

Nawawi. Hadari. 2012. Metode Penelitian Bidang Sosial. Yogyakarta; Gadjah Mada University Press

Paulus, dkk. (2010), Kebudayaan Dayak 'Aktualisasi dan Transformasi', Pontianak: Institut Dayakologi. Satori,

Rosdakarya. Nawawi, Hadari. (2007). Metode Penelitian Bidang Sosial. Yogyakarta: Gajah Mada University Press.

Sujarni, dkk. (2008). Mozaik Dayak Keberagaman Subsuku dan Bahasa Dayak di Kalimantan Barat. Pontianak: Institute Dayakologi.

Irwan Abdullah, dkk. 2008. Agama dan Kearifan lokal dalam tantangan Global. Pascasarjana UGM dan Pustaka Pelajar.Yogyakarta

Sugiyono. 2016. Memahami penelitian Kualitatif. Alfabeta. Bandung.

Sugiyono.2011. Metode Penelitian Kuantitatif, Kualitatif dan R\&B. Alfabeta. Bandung. 